\title{
Space-efficient Indexing of Chess Endgame Tables
}

Article

Published Version

Nalimov, E. V., Haworth, G. M. and Heinz, E. A. (2000) Spaceefficient Indexing of Chess Endgame Tables. ICGA Journal, 23 (3). pp. 148-162. ISSN 1389-6911 Available at https://centaur.reading.ac.uk/4562/

It is advisable to refer to the publisher's version if you intend to cite from the work. See Guidance on citing.

Published version at: http://ticc.uvt.nl/icga/journal/

Publisher: The International Computer Games Association

All outputs in CentAUR are protected by Intellectual Property Rights law, including copyright law. Copyright and IPR is retained by the creators or other copyright holders. Terms and conditions for use of this material are defined in the End User Agreement.

\section{www.reading.ac.uk/centaur}

\section{CentAUR}

Central Archive at the University of Reading

Reading's research outputs online 


\title{
SPACE-EFFICIENT INDEXING OF CHESS ENDGAME TABLES ${ }^{1}$
}

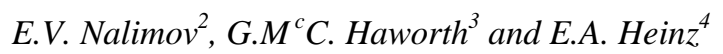 \\ USA and England
}

\begin{abstract}
Chess endgame tables should provide efficiently the value and depth of any required position during play. The indexing of an endgame's positions is crucial to meeting this objective. This paper updates Heinz' previous review of approaches to indexing and describes the latest approach by the first and third authors.

Heinz' and Nalimov's endgame tables (EGTs) encompass the en passant rule and have the most compact index schemes to date. Nalimov's EGTs, to the Distance-to-Mate (DTM) metric, require only $30.6 \times 10^{9}$ elements in total for all the 3-to-5-man endgames and are individually more compact than previous tables. His new index scheme has proved itself while generating the tables and in the 1999 World Computer Chess Championship where many of the top programs used the new suite of EGTs.
\end{abstract}

\section{INTRODUCTION}

The method used to index an endgame positions' values and depths largely determines both the space required and the speed of access during play over the board. It may aim to optimise the one or the other. A variety of approaches have been adopted as the challenges of larger and more complex endgames have been faced.

In this paper, Section 2 is an update of Heinz' review of indexing methods and Section 3 describes in detail Nalimov's new and more compact index scheme. Section 4 describes results achieved and Section 5 summarises and looks ahead to potential developments.

\section{A REVIEW OF SOME INDEX SCHEMES}

A previous paper (Heinz, 1999) surveyed, highlighted and analysed interesting work in the EGT field by Ströhlein (1970), Van den Herik and Herschberg (1985, 1986), Stiller (1989, 1991, 1994, 1995), Thompson (1986, 1991, 1996; ICCA J. Editors, 1992, 1993) and Edwards (1995). It presented a quantitative comparison of the index methods of Thompson (1986, 1996), Edwards (1995) and Heinz for all 3-to-4-man endgames.

Table 1, q.v. also (Heinz, 2000), extends that comparison to 5-man endgames using Thompson's indexes as the baseline. It infers the index range where the authors did not create the EGT, e.g., 4-1 and two-Pawn endgames. $X=Q, R, B$ or $N$ in Table 1 which makes it clear that different constraints were used by the EGT authors to reduce the size of the set of positions which they indexed.

Table 2, which includes the work of Wirth (1999), elicits these constraints and defines which of them have, in effect if not literally, been used by the EGT authors. The list below indicates that Edwards constrains the possible positions the least and Nalimov constrains them the most. For this reason, Edwards' index ranges are the largest and Nalimov's are the smallest. Heinz' EGTs made savings on the indexes of Thompson and Edwards which increase with the number of men, e.g., $3.13 \%$ for $\mathrm{KxK}, 7.67 \%$ for $\mathrm{KxKy}$ and $13.44 \%$ for KxyKz relative to Thompson's indexes.

The next subsections explain the rationale for three of the constraints.

1 This is an edited version of the presentation by Ernst Heinz, delivered on June 18, 1999 at the Advances in Computer Games 9 Conference in Paderborn, Germany, q.v. the Proceedings of the ACG 9 Conference.

Microsoft Corporation, One Microsoft Way, Redmond, WA 98052-6399, USA: eugenen@microsoft.com.

ICL, Sutton's Park Avenue, Reading, RG6 1AZ, UK: guy.haworth@icl.com.

4 M.I.T. Laboratory for Computer Science (NE 43-228). 545 Technology Square, Cambridge, MA 02139, USA: heinz@mit.edu. 


\begin{tabular}{|c|c|c|c|c|c|}
\hline \multirow{2}{*}{$\begin{array}{l}\text { End- } \\
\text { game }\end{array}$} & \multicolumn{2}{|l|}{ Edwards } & \multirow{2}{*}{$\begin{array}{c}\text { Thompson } \\
\text { \# Elements } \\
\end{array}$} & \multicolumn{2}{|r|}{ Heinz } \\
\hline & \# Elements & $+\Delta \%$ & & $+\Delta \%$ & \# Elements \\
\hline KPK & $32 * 64 * 64$ & 33.33 & $24 * 64 * 64$ & -11.82 & $3612 * 24$ \\
\hline KXK & $10 * 64 * 64$ & 38.53 & $462 * 64$ & -3.13 & $462 * 62$ \\
\hline KPKP & $32 * 64 * 64 * 64$ & 77.78 & $24 * 48 * 64 * 64$ & -13.65 & $3612 * 24 * 47$ \\
\hline KPPK & $32 * 64 * 64 * 64$ & 77.78 & $24 * 48 * 64 * 64$ & -55.90 & $3612 * 576$ \\
\hline KPKX & $32 * 64 * 64 * 64$ & 33.33 & $24 * 64 * 64 * 64$ & -15.95 & $3612 * 24 * 61$ \\
\hline KPXK & $32 * 64 * 64 * 64$ & 33.33 & $24 * 64 * 64 * 64$ & -15.95 & $3612 * 24 * 61$ \\
\hline KXXK & $10 * 64 * 64 * 64$ & 38.53 & $462 * 64 * 64$ & -53.83 & $462 * 1891$ \\
\hline KXYK & $10 * 64 * 64 * 64$ & 38.53 & $462 * 64 * 64$ & -7.67 & $462 * 62 * 61$ \\
\hline KXKY & $10 * 64 * 64 * 64$ & 38.53 & $462 * 64 * 64$ & -7.67 & $462 * 62 * 61$ \\
\hline КРPКР & $32 * 64 * 64 * 64 * 64$ & 137.04 & $24 * 48 * 48 * 64 * 64$ & -58.63 & $3612 * 24 * 1081$ \\
\hline KPPPK & $32 * 64 * 64 * 64 * 64$ & 137.04 & $24 * 48 * 48 * 64 * 64$ & -86.15 & $3612 * 8684$ \\
\hline KPPKX & $32 * 64 * 64 * 64 * 64$ & 77.78 & $24 * 48 * 64 * 64 * 64$ & -58.66 & $3612 * 576 * 60$ \\
\hline KPPXK & $32 * 64 * 64 * 64 * 64$ & 77.78 & $24 * 48 * 64 * 64 * 64$ & -58.66 & $3612 * 576 * 60$ \\
\hline KPXKP & $32 * 64 * 64 * 64 * 64$ & 77.78 & $24 * 48 * 64 * 64 * 64$ & -19.05 & $3612 * 24 * 47 * 60$ \\
\hline KPXXK & $32 * 64 * 64 * 64 * 64$ & 33.33 & $24 * 64 * 64 * 64 * 64$ & -60.60 & $3612 * 24 * 1830$ \\
\hline KXXKP & $32 * 64 * 64 * 64 * 64$ & 33.33 & $24 * 64 * 64 * 64 * 64$ & -60.60 & $3612 * 24 * 1830$ \\
\hline KPXKY & $32 * 64 * 64 * 64 * 64$ & 33.33 & $24 * 64 * 64 * 64 * 64$ & -21.20 & $3612 * 24 * 61 * 60$ \\
\hline KPXYK & $32 * 64 * 64 * 64 * 64$ & 33.33 & $24 * 64 * 64 * 64 * 64$ & -21.20 & $3612 * 24 * 61 * 60$ \\
\hline KXYKP & $32 * 64 * 64 * 64 * 64$ & 33.33 & $24 * 64 * 64 * 64 * 64$ & -21.20 & $3612 * 24 * 61 * 60$ \\
\hline KXXXK & $10 * 64 * 64 * 64 * 64$ & 38.53 & $462 * 64 * 64 * 64$ & -85.57 & $462 * 37820$ \\
\hline KXXKY & $10 * 64 * 64 * 64 * 64$ & 38.53 & $462 * 64 * 64 * 64$ & -56.72 & $462 * 62 * 1830$ \\
\hline KXXYK & $10 * 64 * 64 * 64 * 64$ & 38.53 & $462 * 64 * 64 * 64$ & -56.72 & $462 * 62 * 1830$ \\
\hline KXYKZ & $10 * 64 * 64 * 64 * 64$ & 38.53 & $462 * 64 * 64 * 64$ & -13.44 & $462 * 62 * 61 * 60$ \\
\hline KXYZK & $10 * 64 * 64 * 64 * 64$ & 38.53 & $462 * 64 * 64 * 64$ & -13.44 & $462 * 62 * 61 * 60$ \\
\hline
\end{tabular}

Table 1: Comparison of index range computations.

\begin{tabular}{|c|c|c|c|c|c|c|c|}
\hline \# & Identity & Constraint & KT & SE & EH & $\mathbf{C W}$ & EN \\
\hline & & Positions encoded & & & & & \\
\hline 1 & $\mathrm{C}_{\mathrm{W}}$ & wtm positions indexed & - & yes & yes & yes & yes \\
\hline \multirow[t]{3}{*}{2} & $\mathrm{C}_{\mathrm{B}}$ & btm positions indexed & yes & yes & yes & yes & yes \\
\hline & & Placement of the Kings & & & & & \\
\hline & & Pawnless endgames & & & & & \\
\hline 3 & $\mathrm{C}_{8}$ & stmK in a1-d1-d4 & used & used & used & used & used \\
\hline 4 & $\mathrm{C}_{\mathrm{KK} 1}$ & stmK and sntmK on separate squares & used & - & used & used & used \\
\hline 5 & $\mathrm{C}_{\mathrm{TE}}$ & if stmK on a1-d4, stmK in a1-h1-h8 & used & - & used & used & used \\
\hline \multirow[t]{2}{*}{6} & $\mathrm{C}_{\mathrm{KKnP}}$ & exactly 462 wK-bK positions used & used & - & used & used & used \\
\hline & & Endgames with Pawns & & & & & \\
\hline 7 & $\mathrm{C}_{\mathrm{ad}}$ & stmK in a-d & used & used & used & used & used \\
\hline 8 & $\mathrm{C}_{\mathrm{KK} 2}$ & stmK and sntmK on separate squares & - & - & used & used & used \\
\hline \multirow[t]{2}{*}{9} & $\mathrm{C}_{\mathrm{KKP}}$ & exactly 1806 wK-bK positions used & - & - & used & used & used \\
\hline & & Encoding Pawn positions & & & & & \\
\hline 10 & $\mathrm{C}_{\mathrm{P}}$ & Pawns constrained to ranks $2-7$ & used & - & used & used & used \\
\hline \multirow[t]{2}{*}{11} & $\mathrm{C}_{\mathrm{EP}}$ & Pawns capturable en passant included & - & - & used & used & used \\
\hline & & Like men, i.e. of the same type and colour & & & & & \\
\hline \multirow[t]{2}{*}{12} & $\mathrm{C}_{\mathrm{LM}}$ & Saving of $k$ ! for $k$ like men & - & - & used & used & used \\
\hline & & Constraints on squares with more than one man & & & & & \\
\hline 13 & $\mathrm{C}_{\mathrm{S} 1-\mathrm{MM}}$ & No square with two men & - & - & - & - & - \\
\hline 14 & $\mathrm{C}_{\mathrm{S} 2-\mathrm{KPC}}$ & No square with $\mathrm{K}$ and another piece & - & - & used & used & used \\
\hline 15 & $\mathrm{C}_{\mathrm{S} 3-\mathrm{KPW}}$ & No square with $\mathrm{K}$ and a Pawn & - & - & - & - & used \\
\hline 16 & $\mathrm{C}_{\mathrm{S} 4-\mathrm{L} 1}$ & No square with two like pieces & - & - & used & used & used \\
\hline 17 & $\mathrm{C}_{\mathrm{S} 5-\mathrm{L} 2}$ & No square with two like Pawns & - & - & - & used & used \\
\hline 18 & $\mathrm{C}_{\text {S6-SNTM1 }}$ & No square with stm man and sntm piece & - & - & used & used & used \\
\hline \multirow[t]{2}{*}{19} & $\mathrm{C}_{\mathrm{S} 7 \text {-SNTM2 }}$ & No square with man and sntm Pawn & - & - & - & - & - \\
\hline & & Unblockable checks by the stm & & & & & \\
\hline \multirow[t]{2}{*}{20} & $\mathrm{C}_{\mathrm{UC}}$ & No unblockable checks allowed & - & - & - & - & used \\
\hline & & Trimming the index-range & & & & & \\
\hline 21 & $\mathrm{C}_{\mathrm{F}}$ & First positions in a range not broken & - & - & - & - & - \\
\hline 22 & $\mathrm{C}_{\mathrm{L}}$ & Last positions in a range not broken & - & - & - & - & used \\
\hline
\end{tabular}

Table 2: Constraints available to limit the position-sets indexed. ${ }^{5}$ 


\subsection{Constraining a King}

A King is typically constrained to files a-d for endgames with Pawns and to the octant a1-d1-d4 for endgames without Pawns. The choice of the side-to-move King, stmK, as the man to constrain has two advantages:

- the stm King is always present so the constraint can always be exercised,

- there is only one stm King so the effect of the constraint is unambiguous.

In contrast, had a Rook been the constrained man, the software generating and accessing the EGTs would have to decide between the positions below with a Rook on b1 and on $\mathrm{d} 3$ respectively.

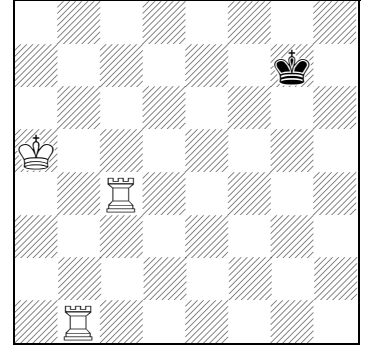

Figure 1: Version 1.

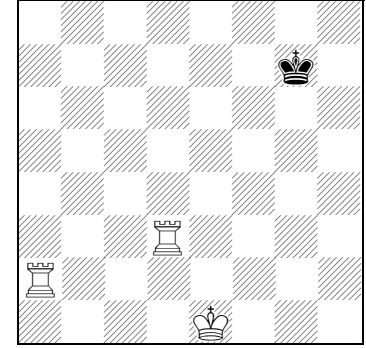

Figure 2: Version 2.

\subsection{Like Men of the Same Type}

Where one side has $k$ men of one type, the index range may be reduced by a factor of $k !=k \times(k-1) \times \ldots \times 1$. The $k$ ! arrangements of $k$ like, labelled men on $q$ given squares are equivalent if the like men are unlabelled. There are $d=\mathrm{C}_{\mathrm{q}, \mathrm{k}}=q ! /[k !(q-k)$ ! ] placements of $k$ like men on $q$ squares where $0 ! \equiv 1$ by definition.

Let $0 \ldots(q-1)$ be the numbers of the available squares and $0 \ldots(d-1)$ the numbers of the $k$-tuple placements of the $k$ like men. The method of transforming one k-tuple into the next determines the numbering:

$\{0,1\} \rightarrow\{0,2\},\{0,3\},\{1,2\},\{1,3\},\{2,3\}$

... advancing the highest-numbered man,

$\{0,1\},\{0,2\},\{1,2\},\{0,3\},\{1,3\} \leftarrow\{2,3\}$ ... retreating the lowest-numbered man.

For the first ordering, the placement $\left\{s_{1}, s_{2}, \ldots, s_{k}\right\}$ of the men on squares $\left\{s_{i} \mid i<j \Rightarrow s_{i}<s_{j}\right\}$ is given index $r$ by the algorithm:

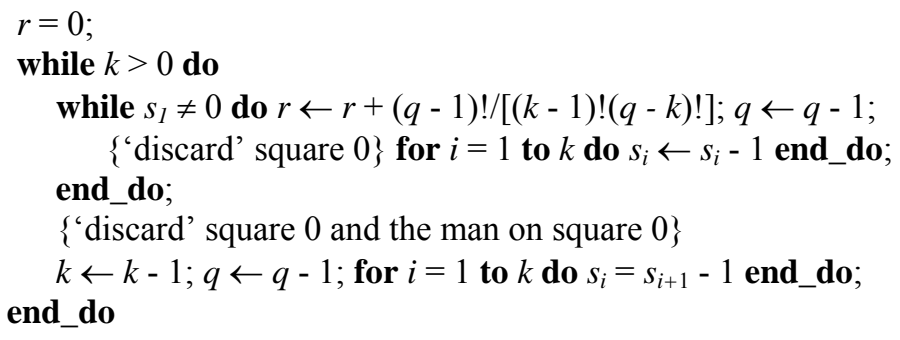

In the second ordering, the placement $\left\{s_{1}, s_{2}, \ldots ., s_{k}\right\}$ of the men on squares $\left\{s_{i} \mid i<j \Rightarrow s_{i}<s_{j}\right\}$ is preceded by placements $\left\{\left\{t_{1}, t_{2}, \ldots, t_{k}\right\} \mid t_{i}<s_{j}(i \leq j) \& t_{i}=s_{i},(i=j+1, \ldots, k) ; j=1, \ldots k\right\}$. It is therefore given index $r$ by the succinct formula:

$n_{j}=$ the number of $j$-tuples of ordered integers taken from $\left[0, s_{j}-1\right]=s_{j} \times\left(s_{j}-1\right) \times \ldots \times \ldots\left(s_{j}-j+1\right) / j ! ; r=\Sigma_{j} n_{j}$.

Thompson, Stiller (1991, 1994, 1995) and Edwards did not take advantage of this economy. Heinz (1999, 2000), Wirth (1999) and Nalimov (1999) do and constrain like pieces ${ }^{6}$, but not necessarily like Pawns, from sharing squares. The appendix features some studies with the theme of esoteric force, that is, unlikely numbers of like men.

6 A piece is a man which is not a Pawn. 


\subsection{First and Last Index not Broken}

If the highest indices in an addressable subrange of the index are marked broken ${ }^{7}$ during the EGT initialisation process, they may simply be removed. If the lowest indices in an addressable subrange are marked broken, they may also be removed but the baseline of the remaining index subrange must be correspondingly reduced. Some illegal positions need not require access to the EGT if the access code incorporates illegality tests.

\section{NALIMOV'S INDEX SCHEME}

The first author has made publicly available an EGT generator and a complete set of 3-to-5-man and some 6man EGTs to the Distance to Mate metric (cf. Hyatt, 2000). The main objectives of their construction are that:

- the colours White and Black are treated symmetrically separate indexes and files for wtm and btm positions; data on both 1-0 and 0-1 wins,

- the EGTs should be practical and efficient to use during play over the board the index for each endgame is the most compact yet produced, time-optimal 8KB EGT blocks of compressed data are decompressed in store, positions for a set configuration of the stm men are clustered together.

This latest index scheme uses the following approach, many of whose principles and optimisations were first articulated by Heinz (1999, 2000):

- the men are notionally placed on the board in the following order: stmK, sntmK, stm men (Q-R-B-N-P), sntm men (Q-R-B-N-P),

- the stmK-sntmK positions are used explicitly: 462 (no Ps) and 1806 (Ps) the index range therefore consists of 462 or 1806 index subranges,

- 'available' squares are numbered $0 \ldots q-1$ in order a1-... h1 - a $2-\ldots-\mathrm{h} 8$,

- the number of squares available to men of a type is calculated knowing: the positions of the Kings and the presence of previously-placed men. Each index subrange for an stmK-sntmK placement is therefore an $n$-space

- $\quad k$ like men of one colour are placed as a set with economy factor $k$ !

- $\quad s t m$ men cannot be placed giving an unblockable $c h e c k^{8}$ to the sntmK,

- positions allowing an en passant capture are indexed in a separate zone.

The net effect is that:

- the squares occupied by the two Kings are not available to any other man,

- the sntm's pieces occupy only previously-unoccupied squares,

- different types of stm pieces share squares in some indexed 'positions',

- 'positions' with Pawns on pieces' squares are indexed.

Nalimov's work can be seen as a significant evolution of Edwards' work which addressed the same objectives but which used less of the available constraints while indexing the positions. The next subsections focus on:

- avoiding unblockable checks, reducing the size of each index subrange

- calculating the dimensions of the $n$-space index subrange

- creating the complete EGT index

- calculating the index of a given position

- indexing positions with the features of en passant and/or castling rights

- improving the performance of EGT access.

\subsection{Avoiding Unblockable Checks}

Let us suppose White is to move: Black cannot be in check. Figure 3 shows that White's men cannot be placed on certain squares as they would give a check which could not be blocked by placing a further man on the board. Thus, Black's King and White's forces constrain the number of arrangements of White's men.

A broken index entry denotes an illegal, unwanted or no position.

An unblockable check cannot be blocked by placing a man on the board. 
The index range for wtm positions will therefore in general be different from that for btm positions. Given the lexicographical way in which endgames are listed, the wtm index range is almost always ${ }^{9}$ less than the btm index range. Where White and Black have the same men, only the btm half of the EGT is computed: the access method flips colours if presented with a wtm position.

White checks from other squares, as in Figure 4, may or may not be blocked by the placement of further men. Positions featuring such checks are indexed but if the sntmK is in check, their indexes are marked as broken during the initialisation phase.

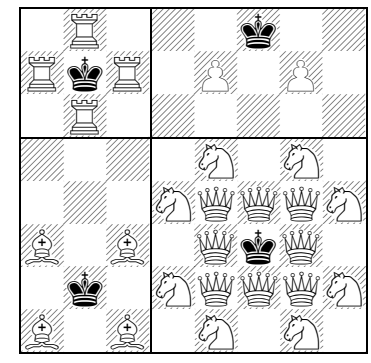

Figure 3: wtm, unblockable checks.

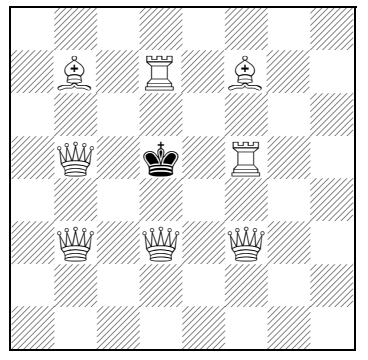

Figure 4: wtm, blockable checks.

\begin{tabular}{|c|c|c|c|c|c|c|}
\hline wK & bK & wQ & wR & wB & wN & wP \\
\hline any & a1 & 59 & 60 & 61 & $60-61$ & $47-48$ \\
\hline any & b1 & 57 & 59 & 60 & $59-60$ & $47-48$ \\
\hline any & c1 & 57 & 59 & 60 & $58-59$ & $47-48$ \\
\hline any & b2 & 54 & 58 & 58 & $58-59$ & $46-47$ \\
\hline a1 & c2 & 54 & 58 & 58 & 56 & 47 \\
\hline a2 & c2 & 54 & 58 & 58 & 56 & 46 \\
\hline a3 & c2 & 54 & 58 & 58 & 57 & 46 \\
\hline any & a3 & 57 & 59 & 60 & $58-59$ & $45-46$ \\
\hline any & c3 & 54 & 58 & 58 & $54-55$ & $44-45$ \\
\hline
\end{tabular}

Table 3: The squares 'available' to each white man with wtm.

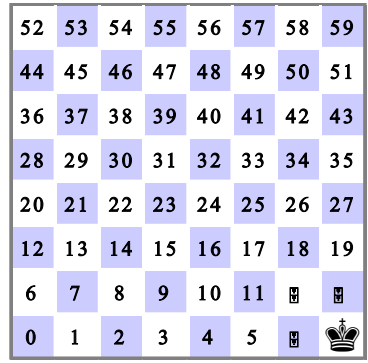

Table 4: wQ squares for bKh1, wtm.

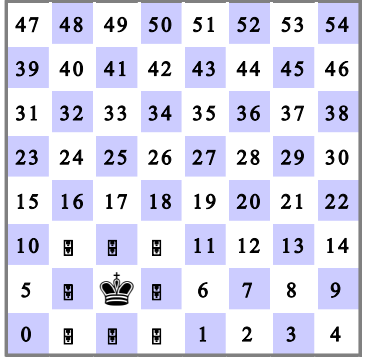

Table 5: wQ squares for $\mathrm{bKc} 2$, wtm.

With White to move, each of the black King's 64 positions determines the number of squares available for each white man, Q, R, B, N or P, as in Table 3. To improve efficiency, Nalimov computes for each man a $64 \times 64$ table giving the reference numbers, for each position of the sntmK, of the squares available to that man. These numbers are modified, given the position of the stmK.

Thus, Tables 4 and 5 give the numbers of the squares available to the wQ in wtm positions with the bK on h1 and $\mathrm{c} 2$ respectively. When the square of the $\mathrm{wK}$ is known, the numbers of the higher-numbered squares decrement by one. The chief reason for the compactness of the indexes described here is the reduction in the number of squares available to men of type $i$ by the avoidance of unblockable checks.

9 The 3-5 man exceptions are KBKN, KBKP, KRKN, KRKP, KBBKQ, KRBKQ, KBPKQ and KRBKP. 


\subsection{The $N$-Space Index Subranges}

The wtm and btm index ranges are 462 or 1806 subranges, each an $n$-space associated with a specific wK-bK placement. Let the qi squares available to the ki non-King men of type $i(i=1, \ldots t)$ be numbered $0 \ldots q i-1$. Then:

- $\quad q i$ is determined as above by the stm, the King positions, the type $i$, and the prior men placed

- $\quad$ there are $d i=\mathrm{C}_{\mathrm{qi}, \mathrm{ki}}=q i$ ! / [ki! (qi - ki)!] placements, $0 \ldots d i-1$, of the type $i$ men

- $\quad$ the index subrange is the $n$-space $[d 1, d 2, \ldots, d t]$, dimension $t$, size $\Pi_{i} d i$

- the subranges' first entries $\left\{\right.$ ind $\left._{\mathrm{\kappa \kappa}}\right\}$ index the wK-bK-position subsets.
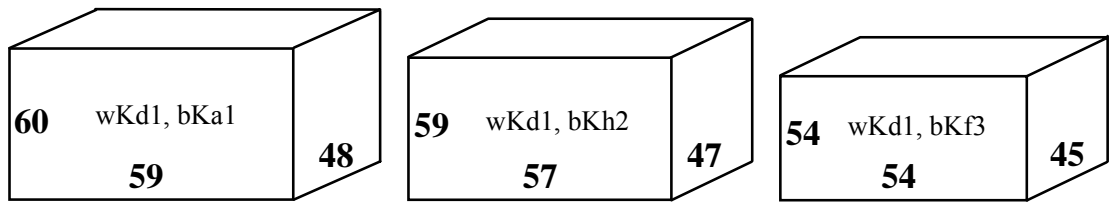

Figure 5:The wtm KQRPK index subranges for three bK positions.

Figure 5 illustrates the index subranges for wtm KQNPK with the wK on $\mathrm{d} 1$ and the bK on a1, h2 and f3. The wQ ranges in turn over 59, 57 and 54 squares, the wN ranges over 60, 59 and 54 squares, and the wP ranges over 48,47 and 45 squares.

A more complex wtm example in the endgame KRRNKP illustrates a calculation involving two like men and also the wK occupying a square denied to the $\mathrm{wN}$. With the wK on al and the bK on $\mathrm{c} 2$, the white Rooks have 58 squares available and, placed as a set, have $58 \times 57 / 2=1653$ placements. The wK occupies a square from which a wN would give an unblockable check. Therefore, the number of squares available to the wN, ignoring as Nalimov does the prior placement of the Rooks, is 57 . There are 47 squares at most available to the bP and on some of these, the bP will be sharing a square with a white man. This sub-index $n$-space therefore has dimensions and size $1653 \times 57 \times 47=4,428,387$.

\subsection{EGT Index Size}

Table 6 illustrates, with the wtm index of endgame KQRK, the impact of minimising the number of squares qi available to men of type $i$. The economy of this index approach is clear when compared with other possibilities.

The lookup tables which effect and expedite the indexing occupy some 200KBytes per 3-2 endgame and up to 350KBytes for 4-1 endgames.

\begin{tabular}{|c|l|c|c|}
\hline Constraints & Notes & Computation & Size \\
\hline & The naive index-scheme & $64 * 64 * 64 * 64$ & $16,777,216$ \\
\hline $\mathrm{C}_{\mathrm{sl} 1-\mathrm{mm}}$ & no square shared & $64 * 63 * 62 * 61$ & $15,249,024$ \\
\hline $\mathrm{C}_{8}$ & Edwards' index-range & $10 * 64 * 64 * 64$ & $2,621,440$ \\
\hline $\mathrm{C}_{8} \& \mathrm{C}_{\mathrm{s} 1-\mathrm{mm}}$ & wK in octant; no square shared & $10 * 63 * 62 * 61$ & $2,382,660$ \\
\hline $\mathrm{C}_{\mathrm{KKnP}}$ & Thompson's index-range & $462 * 64 * 64$ & $1,892,352$ \\
\hline $\mathrm{C}_{\mathrm{KKnP}} \& \mathrm{C}_{\mathrm{sl}-\mathrm{mm}}$ & Heinz' and Wirth's index-range & $462 * 62 * 61$ & $1,747,284$ \\
\hline $\mathrm{C}_{\mathrm{KKnP}} \& \mathrm{C}_{\mathrm{uc}(\mathrm{Q})}$ & 3 squares denied to the wQ & $462 * 59 * 61$ & $1,662,738$ \\
\hline $\mathrm{C}_{\mathrm{KKnP}} \& \mathrm{C}_{\mathrm{uc}(\mathrm{QR})}$ & $\ldots$ and 2 sq. denied to the wR & $462 * 59 * 59$ & $1,608,222$ \\
\hline $\mathrm{C}_{\mathrm{KKnP}} \& \mathrm{C}_{\mathrm{uc}} \& \mathrm{C}_{\mathrm{L}}$ & Nalimov's index-range & $(57 * 58+\ldots)-366$ & $1,500,276$ \\
\hline $\mathrm{C}_{\mathrm{KKnP}} \& \mathrm{C}_{\mathrm{uc}} \& \mathrm{C}_{\mathrm{sl}-\mathrm{mm}} \& \mathrm{C}_{\mathrm{L}}$ & Nalimov, but no square shared & $(57 * 57+\ldots)-360$ & $1,474,713$ \\
\hline
\end{tabular}

Table 6: Index ranges for wtm KQRK positions under various constraints.

The calculations for different types of man allow men to occupy the same square, e.g., in KQRK, KQPK or KQKP. However, the net reduction in the index ranges is significant and certainly much greater than the workspace required for the lookup tables. 


\subsection{The Index of a Position}

As in Subsection 2.2, let the men of type $i$ be placed on squares $\left\{s_{i, 1}, \ldots, s_{\mathrm{i}, \mathrm{ki}}\right\}$ as numbered for their type given prior placements. Then:

- $\quad$ the type $i$ men are deemed to be in placement $r i \in[0, d i-1], i=1 \ldots t$,

- the position has co-ordinates $[r 1, \ldots ., r t]$ in the $n$-space $[d 1, d 2, \ldots, d t]$,

- $\quad$ the position's $n$-space index, subind $=\sum_{\mathrm{i}} r_{i} \times \Pi_{j>i} d_{j}$ where $j \leq t+1$ and $d_{t+1} \equiv 1$,

- $\quad$ assuming KK-placement $\kappa \kappa$, the position's index in the EGT is ind ${ }_{\kappa \kappa}+$ subind.

\subsection{Indexing the En Passant Positions}

RETRO (Forthoffer, Rasmussen and Dekker, 1989) uniquely generated EGTs recognising both en passant capture and castling. Recently, Heinz, Moreland, Nalimov (Heinz, 2000) and Wirth (1999) have indexed the positions featuring a possible en passant capture. Nalimov does so in a separate zone of the stm index after the main index. Let us assume that it is btm. A white Pawn will be on $x 4, x$ in $a-h$, and a black Pawn will be on an adjacent file, giving 14 potential placements of these two Pawns instead of 2,256. Further, as White has just moved a Pawn from $x 2$ to $x 4$, squares $x 2$ and $x 3$ are not available to be occupied by other men.

Kings are still placed in their 1806 positions and stm pieces are still constrained by the avoidance of unblockable checks.

The concept of a separate index zone for positions with a specific feature, in this case potential e.p. capture, generalises to the provision of separate index zones for positions with specific subsets of the five features:

stm can make an en passant capture,

White and/or Black can castle on the a-side and/or the h-side.

The full representation of en passant and castling rights, not included in Nalimov's EGTs, involves $2^{5}$ zones of positions rather than the usual one zone. However, as each feature constrains at least one man and reduces the index range by a factor of at least 60,31 of the zones are relatively small. It may be helpful to place constrained men first but no fundamentally new principles of indexing are required.

\subsection{EGT Access Performance}

Because White, for example, submits a number of btm positions to the EGT, the placement of stm (black) men before their sntm equivalents also tends to cluster White's accesses to the file. Also, because chess engines probe the EGT at several nodes in their search tree, Nalimov wrote an efficient lookup function which manages an LRU, least-recently used, cache of EGT values. Experiments with CRAFTY show that the new index scheme facilitates much better caching behaviour than others, particularly with parallel search on symmetric multiprocessors.

Nalimov's EGT files are compressed into $8 \mathrm{~KB}$ blocks, the technique exploiting common sequences and Huffman coding. The block size optimises runtime performance rather than space. It is usually more efficient to decompress the blocks at runtime in store than to work with uncompressed files.

\begin{tabular}{|c||c||c|c|c|}
\hline All Endgames & Nalimov & Heinz & Thompson & Edwards \\
\hline \# Elements, wtm & $14,702,353,093$ & $16,807,619,304$ & $25,936,842,240$ & $37,046,484,992$ \\
\hline Extra Elements & & $2,105,266,211$ & $11,234,489,147$ & $22,344,131,899$ \\
\hline$+\Delta \%$ & - & 14.32 & 76.41 & 151.98 \\
\hline \hline \# Elements, btm & $15,909,833,876$ & $16,807,619,304$ & $25,936,842,240$ & $37,046,484,992$ \\
\hline Extra Elements & & $897,785,428$ & $10,027,008,364$ & $21,136,651,116$ \\
\hline$+\Delta \%$ & & 5.64 & 63.02 & 132.85 \\
\hline \hline \# Elements, all & $30,612,186,969$ & $33,615,238,608$ & $51,873,684,480$ & $74,092,969,984$ \\
\hline Extra Elements & - & $3,003,051,639$ & $21,261,497,511$ & $43,480,783,015$ \\
\hline$+\Delta \%$ & - & 9.81 & 69.45 & 142.04 \\
\hline
\end{tabular}

Table 7: Summary of 3-to-5-man index range sizes. 


\begin{tabular}{|c|c|c|c|c|c|c|c|c|c|c|c|c|c|c|}
\hline \multirow[b]{2}{*}{ Endgame } & \multicolumn{2}{|c|}{$1-0$} & \multicolumn{2}{|c|}{$0-1$} & \multirow[b]{2}{*}{ Endgame } & \multicolumn{2}{|c|}{$1-0$} & \multicolumn{2}{|c|}{$0-1$} & \multirow[b]{2}{*}{ Endgame } & \multicolumn{2}{|c|}{ 1-0 } & \multicolumn{2}{|c|}{$0-1$} \\
\hline & wtm & btm & wtm & btm & & wtm & btm & wtm & btm & & wtm & btm & wtm & btm \\
\hline KBBBK & 16 & 19 & - & - & KPPK & 32 & 32 & - & - & KQRK & 6 & 16 & - & - \\
\hline KBBK & 19 & 19 & - & - & КРРКВ & 43 & 43 & 3 & 4 & KQRKB & 29 & 29 & - & - \\
\hline KВBKB & 22 & 22 & 1 & 2 & KPPKN & 50 & 50 & 16 & 17 & KQRKN & 40 & 40 & 0 & 1 \\
\hline KBBKN & 78 & 78 & 0 & 1 & КРPКР & 127 & 127 & 42 & 43 & KQRKP & 40 & 67 & 35 & 43 \\
\hline КВBKP & 74 & 73 & 82 & 83 & KPPKQ & 124 & 100 & 41 & 41 & KQRKQ & 67 & 67 & 37 & 38 \\
\hline KBBKQ & 21 & 20 & 81 & 81 & KPPKR & 54 & 53 & 41 & 40 & KQRKR & 34 & 35 & 2 & 20 \\
\hline KBBKR & 23 & 22 & 30 & 31 & KPPPK & 33 & 33 & - & - & KQRNK & 5 & 16 & - & - \\
\hline KBBNK & 33 & 33 & - & - & KQBBK & 6 & 19 & - & - & KQRPK & 7 & 16 & - & - \\
\hline KBBPK & 30 & 31 & - & - & KQBK & 8 & 10 & - & - & KQRRK & 4 & 7 & - & - \\
\hline KBK & - & - & - & - & KQBKB & 17 & 17 & 1 & 2 & KRBBK & 12 & 19 & - & - \\
\hline KBKB & 1 & 0 & 0 & 1 & KQBKN & 21 & 21 & 0 & 1 & KRBK & 16 & 16 & - & - \\
\hline KBKN & 1 & 0 & 0 & 1 & KQBKP & 32 & 33 & 17 & 24 & KRBKB & 30 & 30 & 1 & 2 \\
\hline KBKP & 1 & 0 & 19 & 29 & KQBKQ & 33 & 33 & 23 & 24 & KRBKN & 40 & 40 & 0 & 1 \\
\hline KBNK & 33 & 33 & - & - & KQBKR & 40 & 40 & 25 & 30 & KRBKP & 28 & 36 & 65 & 70 \\
\hline KBNKB & 39 & 39 & 1 & 2 & KQBNK & 7 & 33 & - & - & KRBKQ & 21 & 20 & 70 & 70 \\
\hline KBNKN & 107 & 106 & 0 & 1 & KQBPK & 9 & 31 & - & - & KRBKR & 65 & 64 & 26 & 30 \\
\hline KBNKP & 104 & 104 & 54 & 55 & KQK & 10 & 10 & - & - & KRBNK & 29 & 33 & - & - \\
\hline KBNKQ & 36 & 35 & 53 & 53 & KQKB & 17 & 17 & - & - & KRBPK & 16 & 31 & - & - \\
\hline KBNKR & 36 & 35 & 39 & 41 & KQKN & 21 & 21 & - & - & KRK & 16 & 16 & - & - \\
\hline KBNNK & 34 & 34 & - & - & KQKP & 28 & 28 & 10 & 29 & KRKB & 29 & 29 & - & - \\
\hline KBNPK & 33 & 33 & - & - & KQKQ & 13 & 12 & 12 & 13 & KRKN & 40 & 40 & 0 & 1 \\
\hline KBPK & 31 & 31 & - & - & KQKR & 35 & 35 & 18 & 19 & KRKP & 26 & 32 & 42 & 43 \\
\hline КВРКВ & 51 & 50 & 2 & 3 & KQNK & 9 & 10 & - & - & KRKR & 19 & 19 & 19 & 19 \\
\hline KBPKN & 100 & 96 & 7 & 8 & KQNKB & 17 & 17 & 0 & 1 & KRNK & 16 & 16 & - & - \\
\hline КВРКР & 67 & 67 & 50 & 51 & KQNKN & 21 & 21 & 0 & 1 & KRNKB & 31 & 31 & 0 & 1 \\
\hline KBPKQ & 35 & 34 & 50 & 50 & KQNKP & 30 & 41 & 22 & 29 & KRNKN & 37 & 40 & 0 & 1 \\
\hline KBPKR & 45 & 44 & 38 & 39 & KQNKQ & 41 & 41 & 23 & 24 & KRNKP & 29 & 29 & 63 & 68 \\
\hline KBPPK & 25 & 32 & - & - & KQNKR & 38 & 38 & 38 & 41 & KRNKQ & 20 & 19 & 69 & 69 \\
\hline KK & - & - & - & - & KQNNK & 8 & 9 & - & - & KRNKR & 37 & 36 & 39 & 41 \\
\hline KNK & - & - & - & - & KQNPK & 9 & 27 & - & - & KRNNK & 15 & 16 & - & - \\
\hline KNKN & 1 & 0 & 0 & 1 & KQPK & 10 & 28 & - & - & KRNPK & 17 & 27 & - & - \\
\hline KNKP & 7 & 6 & 28 & 29 & KQPKB & 28 & 29 & 1 & 2 & KRPK & 16 & 28 & - & - \\
\hline KNNK & 1 & 0 & - & - & KQPKN & 30 & 30 & 7 & 8 & KRPKB & 73 & 73 & 1 & 2 \\
\hline KNNKB & 4 & 3 & 0 & 1 & KQPKP & 105 & 122 & 14 & 34 & KRPKN & 54 & 54 & 7 & 8 \\
\hline KNNKN & 7 & 6 & 0 & 1 & KQPKQ & 124 & 123 & 28 & 29 & KRPKP & 56 & 68 & 100 & 103 \\
\hline KNNKP & 115 & 114 & 73 & 74 & KQPKR & 37 & 43 & 27 & 33 & KRPKQ & 68 & 59 & 103 & 104 \\
\hline KNNKQ & 1 & 0 & 72 & 72 & KQPPK & 9 & 32 & - & - & KRPKR & 74 & 74 & 28 & 33 \\
\hline KNNKR & 3 & 2 & 40 & 41 & KQQBK & 4 & 8 & - & - & KRPPK & 15 & 32 & - & - \\
\hline KNNNK & 21 & 21 & - & - & KQQK & 4 & 10 & - & - & KRRBK & 10 & 16 & - & - \\
\hline KNNPK & 28 & 28 & - & - & KQQKB & 15 & 17 & - & - & KRRK & 7 & 16 & - & - \\
\hline KNPK & 27 & 28 & - & - & KQQKN & 19 & 21 & - & - & KRRKB & 29 & 29 & - & - \\
\hline KNPKB & 43 & 42 & 8 & 9 & KQQKP & 22 & 30 & 2 & 13 & KRRKN & 40 & 40 & 0 & 1 \\
\hline KNPKN & 97 & 97 & 3 & 7 & KQQKQ & 30 & 30 & 12 & 13 & KRRKP & 33 & 40 & 40 & 50 \\
\hline KNPKP & 57 & 57 & 57 & 58 & KQQKR & 35 & 35 & 2 & 19 & KRRKQ & 29 & 28 & 49 & 49 \\
\hline KNPKQ & 41 & 33 & 62 & 55 & KQQNK & 4 & 9 & - & - & KRRKR & 31 & 31 & 2 & 20 \\
\hline KNPKR & 44 & 43 & 66 & 67 & KQQPK & 4 & 10 & - & - & KRRNK & 10 & 16 & - & - \\
\hline KNPPK & 32 & 32 & - & - & KQQQK & 3 & 4 & - & - & KRRPK & 14 & 16 & - & - \\
\hline KPK & 28 & 28 & - & - & KQQRK & 4 & 6 & - & - & KRRRK & 5 & 7 & - & - \\
\hline KPKP & 33 & 33 & 33 & 33 & KQRBK & 5 & 16 & -1 & - & & & & & \\
\hline
\end{tabular}

Table 8: Maximal DTM figures for 1-0 and 0-1 wins, wtm and btm.

\section{RESULTS}

The first author has computed all 3-to-5-man DTM EGTs (Hyatt, 2000; Tamplin, 2000). His robust code also generated KQQKQQ on request for the Kasparov-World game (Nalimov, Wirth, and Haworth, 1999) and has now produced further 6-man EGTs including the deepest to date, KRNKNN.

The space-efficient index scheme incorporates the en passant rule and requires only $30.6 \times 10^{9}$ elements in total for the 3-to-5-man endgames. It is better for each endgame than previous schemes. By comparison, Heinz' 
scheme would have required $33.6 \times 10^{9}(+9.81 \%)$, Thompson's $51.9 \times 10^{9}$ elements $(+69.45 \%)$ and Edwards' $74.1 \times 10^{9}$ elements $(+142.04 \%)$, see Table 7 .

The question of data integrity always arises with results which are not self-evidently correct. Nalimov runs a separate self-consistency phase on each EGT after it is generated. Both his EGTs and those of Wirth (1999) yield exactly the same number of mutual zugzwangs of each type $(=/ 1-0,0-1 /=$ and $0-1 / 1-0)$ for all 2-to-5-man endgames (Haworth, 2000) and no errors have yet been discovered.

DARKTHought (Heinz, 1997), using Heinz' index-scheme and EGTs, competed in WMCC 1997 (Hamlen and Feist, 1997) and WCCC 1999 (Beal, 1999). Nalimov's new index scheme has proved its practicality over the board, particularly in WCCC 1999 where it was used by ten competitors including the leading SHREDDER, FRITZ, JUNIOR and NIMZO.

Table 8 gives the depths of DTM-maximal 1-0 and 0-1 wins, wtm and btm. The tables in the Appendix compare Nalimov's index sizes with others' and the statistics on residual broken positions in Nalimov's EGTs. This is the most complete tabulation of 2-5-man endgame data published so far.

\section{SUMMARY}

The index design is the key to computing compact and efficiently used chess endgame tables. The first author has exploited the available constraints on the positions to be indexed in the best way to date.

The result is that a robust and efficient EGT generation code, a complete suite of 145 3-to-5-man EGTs, and some 30 6-man EGTs are now publicly available.

Further progress in the compression of index ranges is possible. There can be less occurrences of men sharing squares if Pawns are notionally placed first (Karrer, 2000) and the presence of prior stm men is recognised.

\section{ACKNOWLEDGEMENTS}

Our thanks to an anonymous referee who contributed the succinct formula of Subsection 2.2 for indexing $k$ like men. Also, thanks to Helmut Conrady, Peter Karrer and Lars Rasmussen whose combined contribution confirmed the maxDTM figures of Table 8 with two corrections, and substantiated them with the sets of maxDTM positions.

\section{REFERENCES}

Beal, D.F. (1999). The $9^{\text {th }}$ World Computer-Chess Championship: the Search-Engine Features of the Programs. ICCA Journal, Vol. 22, No. 3, pp. 160-163. ISSN 0920-234X.

Beasley J. \& Whitworth, T. (1996). Endgame Magic, esp. p. 158. Batsford. ISBN 0-7134-7971-X.

Bondar, I. (1998). Four Queen study. Shakhmatnaya kompozitsia No. 22. See also EG No. 137, p. 188 (2000).

Edwards, S.J. (1995). Comments on Barth's Article "Combining Knowledge and Search to Yield Infallible Endgame Programs." ICCA Journal, Vol. 18, No. 4, p. 219-225.

Elkies, N. (2000). SSSS-Q. EG, No. 137, p. 158. ISSN-0012-7671.

Forthoffer, D., Rasmussen, L. and Dekker, S.T. (1989). A Correction to Some KRKB-Database Results. ICCA Journal, Vol. 12, No. 1, pp. 25-27.

Hamlen, J. and Feist, M. (1997). Report on the $15^{\text {th }}$ World Microcomputer Chess Championship. ICCA Journal, Vol. 20. No. 4, pp. 254-255.

Haworth, G.M ${ }^{c}$ C. (2000). Private communication to Karrer, Nalimov, Rasmussen and Wirth. 
Heinz, E.A. (1997). How DARKTHought plays Chess. ICCA Journal, Vol. 20, No. 3, pp. 166-176.

Heinz, E.A. (1999). Endgame Databases and Efficient Index Schemes for Chess. ICCA Journal, Vol. 22, No. 1, pp. 22-32.

Heinz, E.A. (2000). Scalable Search in Computer Chess. Vieweg Verlag (Morgan Kaufmann), Braunschweig/Wiesbaden. ISBN 3-5280-5732-7.

Herik, H.J. van den and Herschberg, I.S. (1985). The Construction of an Omniscient Endgame Database. ICCA Journal, Vol. 8, No. 2, pp. 66-87.

Herik, H.J. van den and Herschberg, I.S. (1986). A Data Base on Data Bases. ICCA Journal, Vol. 9, No. 1, pp. 29-34.

Hyatt, R. (2000). ftp://ftp.cis.uab.edu/pub/hyatt/TB/. Server providing CRAFTY and Nalimov's EGTs and statistics.

ICCA J. Editors (1992). Thompson: All About Five Men. ICCA Journal, Vol. 15, No. 3, pp. 140-143.

ICCA J. Editors (1993). Thompson: Quintets with Variations. ICCA Journal, Vol. 16, No. 2, pp. 86-90.

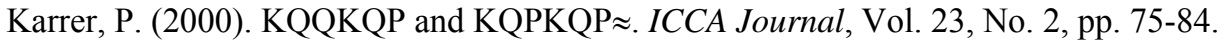

Nalimov, E.V., Wirth, C., and Haworth, G.M ${ }^{c}$ C. (1999). KQQKQQ and the Kasparov-World Game. ICCA Journal, Vol. 22, No. 4, pp. 195-212.

Savin, P.I. and Plaksin, N.M. (1987). The Art of Chess Composition. Kishinev.

Stiller, L.B. (1989). Parallel Analysis of Certain Endgames. ICCA Journal, Vol. 12, No. 2, pp. 55-64.

Stiller, L.B. (1991). Group Graphs and Computational Symmetry on Massively Parallel Architecture. The Journal of Supercomputing, Vol. 5, No. 2, pp. 99-117.

Stiller, L.B. (1994). Multilinear Algebra and Chess Endgames. Games of No Chance (ed. R.J. Nowakowski), pp. 151-192. MSRI Publications, v29, CUP, Cambridge, England. ISBN 0-5215-7411-0. Reprinted in paperback (1996). ISBN 0-5216-4652-9.

Stiller, L.B. (1995). Exploiting Symmetry of Parallel Architectures. Ph.D. Thesis, Department of Computer Sciences, The John Hopkins University, Baltimore, Md.

Ströhlein, T. (1970). Untersuchungen über kombinatorische Spiele. Dissertation, Fakultät für Allgemeine Wissenschaften der Technischen Hochschule München.

Tamplin, J. (2000). http://chess.liveonthenet.com/chess/endings/index.shtml. Access to Thompson's 5-man EGTs and maxDTC positions, and to Nalimov's 3- to 6-man EGTs.

Thompson, K. (1986). Retrograde Analysis of Certain Endgames. ICCA Journal, Vol. 9, No. 3, pp. 131-139.

Thompson, K. (1991). Chess Endgames Vol. 1. ICCA Journal, Vol. 14, No. 1, p. 22.

Thompson, K. (1996). 6-Piece Endgames. ICCA Journal, Vol. 19, No. 4, pp. 215-226.

Troitzkiü, A.A. (1912). KNNNNKQ Study. Deutsche Schachzeitung.

Troitzkiı̌, A.А. (1934). Два коня против пешек (теоретический очерк). Сборник шахматных этюдов, рр. 248-288. Leningrad. [Dva Konya protiv pešek. Sbornik šakhmatnykh étyudov.] Partly republished (1937) in Collection of Chess Studies, with a Supplement on the Theory of the End-Game of Two Knights against Pawns. (trans. A.D. Pritzson), David McKay Company, the latter again re-published (1985) by Olms, Zürich.

Wirth, C. and Nievergelt, J. (1999). Exhaustive and Heuristic Retrograde Analysis of the KPPKP Endgame. ICCA Journal, Vol. 22, No. 2, pp. 67-80. 


\section{APPENDIX}

This appendix provides complete data covering all 2-to-5-man endgames. Tables 9-13 compare the index sizes of Thompson's, Edwards' and Heinz' EGTs with the index size of Nalimov's EGTs as follows:

3-man endgames (Table 9), 4-man endgames (Table 10), 3-2-man pawnless endgames (Table 11),

3-2-man endgames with Pawns (Table 12) and 4-1 man endgames (Table 13).

Tables $14 \mathrm{a}$ and $14 \mathrm{~b}$ give the number and \% of residual broken positions per endgame in Nalimov's EGTs.

Three studies with unlikely numbers of like men are featured here, q.v. Figures 6-8 below.

\begin{tabular}{|c|c|c|c|c|c|c|c|c|}
\hline & wtm & KT & SE & EH & btm & KT & SE & EH \\
\hline Endgame & \# Elements & $+\Delta \%$ & $+\Delta \%$ & $+\Delta \%$ & \# Elements & $+\Delta \%$ & $+\Delta \%$ & $+\Delta \%$ \\
\hline KBK & 27,243 & 8.53 & 50.35 & 5.14 & 28,644 & 3.23 & 43.00 & 0.00 \\
\hline KNK & 26,282 & 12.50 & 55.85 & 8.99 & 28,644 & 3.23 & 43.00 & 0.00 \\
\hline KPK & 81,664 & 20.38 & 60.50 & 6.15 & 84,012 & 17.01 & 56.02 & 3.19 \\
\hline KQK & 25,629 & 15.37 & 59.82 & 11.76 & 28,644 & 3.23 & 43.00 & 0.00 \\
\hline KRK & 27,030 & 9.39 & 51.54 & 5.97 & 28,644 & 3.23 & 43.00 & 0.00 \\
\hline Aggregate & 187,848 & 15.29 & 57.00 & 7.14 & 198,588 & 9.06 & 48.50 & 1.35 \\
\hline
\end{tabular}

Table 9: Comparison of index sizes for 3-man endgames.

\begin{tabular}{|c|c|c|c|c|c|c|c|c|}
\hline & wtm & KT & SE & EH & btm & KT & SE & EH \\
\hline Endgame & \# Elements & $+\Delta \%$ & $+\Delta \%$ & $+\Delta \%$ & \# Elements & $+\Delta \%$ & $+\Delta \%$ & $+\Delta \%$ \\
\hline KВBK & 789,885 & 139.57 & 231.88 & 10.60 & 873,642 & 116.60 & 200.06 & 0.00 \\
\hline KBKB & $1,661,823$ & 13.87 & 57.74 & 5.14 & $1,661,823$ & 13.87 & 57.74 & 5.14 \\
\hline KBKN & $1,661,823$ & 13.87 & 57.74 & 5.14 & $1,603,202$ & 18.04 & 63.51 & 8.99 \\
\hline KBKP & $5,112,000$ & 23.07 & 64.10 & 3.44 & $4,981,504$ & 26.30 & 68.40 & 6.15 \\
\hline KBNK & $1,550,620$ & 22.04 & 69.06 & 12.68 & $1,747,284$ & 8.30 & 50.03 & 0.00 \\
\hline КВРК & $4,817,128$ & 30.61 & 74.14 & 9.77 & $5,124,732$ & 22.77 & 63.69 & 3.19 \\
\hline KNKN & $1,603,202$ & 18.04 & 63.51 & 8.99 & $1,603,202$ & 18.04 & 63.51 & 8.99 \\
\hline KNKP & $4,931,904$ & 27.57 & 70.09 & 7.22 & $4,981,504$ & 26.30 & 68.40 & 6.15 \\
\hline KNNK & 735,304 & 157.36 & 256.51 & 18.81 & 873,642 & 116.60 & 200.06 & 0.00 \\
\hline KNPK & $4,648,581$ & 35.34 & 80.46 & 13.75 & $5,124,732$ & 22.77 & 63.69 & 3.19 \\
\hline KPKP & $3,863,492$ & 22.13 & 117.13 & 5.46 & $3,863,492$ & 22.13 & 117.13 & 5.46 \\
\hline KРPK & $1,806,671$ & 161.18 & 364.31 & 15.16 & $1,912,372$ & 146.74 & 338.65 & 8.79 \\
\hline KQBK & $1,512,507$ & 25.11 & 73.32 & 15.52 & $1,747,284$ & 8.30 & 50.03 & 0.00 \\
\hline KQKB & $1,563,735$ & 21.01 & 67.64 & 11.74 & $1,661,823$ & 13.87 & 57.74 & 5.14 \\
\hline KQKN & $1,563,735$ & 21.01 & 67.64 & 11.74 & $1,603,202$ & 18.04 & 63.51 & 8.99 \\
\hline KQKP & $4,810,080$ & 30.80 & 74.40 & 9.94 & $4,981,504$ & 26.30 & 68.40 & 6.15 \\
\hline KQKQ & $1,563,735$ & 21.01 & 67.64 & 11.74 & $1,563,735$ & 21.01 & 67.64 & 11.74 \\
\hline KQKR & $1,563,735$ & 21.01 & 67.64 & 11.74 & $1,649,196$ & 14.74 & 58.95 & 5.95 \\
\hline KQNK & $1,459,616$ & 29.65 & 79.60 & 19.71 & $1,747,284$ & 8.30 & 50.03 & 0.00 \\
\hline KQPK & $4,533,490$ & 38.78 & 85.04 & 16.64 & $5,124,732$ & 22.77 & 63.69 & 3.19 \\
\hline KQQK & 698,739 & 170.82 & 275.17 & 25.03 & 873,642 & 116.60 & 200.06 & 0.00 \\
\hline KQRK & $1,500,276$ & 26.13 & 74.73 & 16.46 & $1,747,284$ & 8.30 & 50.03 & 0.00 \\
\hline KRBK & $1,594,560$ & 18.68 & 64.40 & 9.58 & $1,747,284$ & 8.30 & 50.03 & 0.00 \\
\hline KRKB & $1,649,196$ & 14.74 & 58.95 & 5.95 & $1,661,823$ & 13.87 & 57.74 & 5.14 \\
\hline KRKN & $1,649,196$ & 14.74 & 58.95 & 5.95 & $1,603,202$ & 18.04 & 63.51 & 8.99 \\
\hline KRKP & $5,072,736$ & 24.02 & 65.37 & 4.24 & $4,981,504$ & 26.30 & 68.40 & 6.15 \\
\hline KRKR & $1,649,196$ & 14.74 & 58.95 & 5.95 & $1,649,196$ & 14.74 & 58.95 & 5.95 \\
\hline KRNK & $1,538,479$ & 23.00 & 70.39 & 13.57 & $1,747,284$ & 8.30 & 50.03 & 0.00 \\
\hline KRPK & $4,779,530$ & 31.63 & 75.51 & 10.64 & $5,124,732$ & 22.77 & 63.69 & 3.19 \\
\hline KRRK & 777,300 & 143.45 & 237.25 & 12.39 & 873,642 & 116.60 & 200.06 & 0.00 \\
\hline Aggregate & $72,662,274$ & 34.34 & 87.60 & 9.97 & $76,439,484$ & 27.70 & 78.33 & 4.54 \\
\hline
\end{tabular}

Table 10: Comparison of index sizes for 4-man endgames. 


\begin{tabular}{|c|c|c|c|c|c|c|c|c|}
\hline & wtm & KT & SE & EH & btm & KT & SE & EH \\
\hline Endgame & \# Elements & $+\Delta \%$ & $+\Delta \%$ & $+\Delta \%$ & \# Elements & $+\Delta \%$ & $+\Delta \%$ & $+\Delta \%$ \\
\hline KBBKB & $47,393,100$ & 155.54 & 254.00 & 10.60 & $49,854,690$ & 142.93 & 236.52 & 5.14 \\
\hline KBBKN & $47,393,100$ & 155.54 & 254.00 & 10.60 & $48,096,060$ & 151.81 & 248.83 & 8.99 \\
\hline KBBKQ & $47,393,100$ & 155.54 & 254.00 & 10.60 & $46,912,050$ & 158.17 & 257.63 & 11.74 \\
\hline KBBKR & $47,393,100$ & 155.54 & 254.00 & 10.60 & $49,475,880$ & 144.79 & 239.10 & 5.95 \\
\hline KBNKB & $93,037,200$ & 30.17 & 80.33 & 12.68 & $99,709,380$ & 21.46 & 68.26 & 5.14 \\
\hline KBNKN & $93,037,200$ & 30.17 & 80.33 & 12.68 & $96,192,120$ & 25.90 & 74.41 & 8.99 \\
\hline KBNKQ & $93,037,200$ & 30.17 & 80.33 & 12.68 & $93,824,100$ & 29.08 & 78.82 & 11.74 \\
\hline KBNKR & $93,037,200$ & 30.17 & 80.33 & 12.68 & $98,951,760$ & 22.39 & 69.55 & 5.95 \\
\hline KNNKB & $44,118,240$ & 174.51 & 280.28 & 18.81 & $49,854,690$ & 142.93 & 236.52 & 5.14 \\
\hline KNNKN & $44,118,240$ & 174.51 & 280.28 & 18.81 & $48,096,060$ & 151.81 & 248.83 & 8.99 \\
\hline KNNKQ & $44,118,240$ & 174.51 & 280.28 & 18.81 & $46,912,050$ & 158.17 & 257.63 & 11.74 \\
\hline KNNKR & $44,118,240$ & 174.51 & 280.28 & 18.81 & $49,475,880$ & 144.79 & 239.10 & 5.95 \\
\hline KQBKB & $90,750,420$ & 33.45 & 84.87 & 15.52 & $99,709,380$ & 21.46 & 68.26 & 5.14 \\
\hline KQBKN & $90,750,420$ & 33.45 & 84.87 & 15.52 & $96,192,120$ & 25.90 & 74.41 & 8.99 \\
\hline KQBKQ & $90,750,420$ & 33.45 & 84.87 & 15.52 & $93,824,100$ & 29.08 & 78.82 & 11.74 \\
\hline KQBKR & $90,750,420$ & 33.45 & 84.87 & 15.52 & $98,951,760$ & 22.39 & 69.55 & 5.95 \\
\hline KQNKB & $87,576,960$ & 38.29 & 91.57 & 19.71 & $99,709,380$ & 21.46 & 68.26 & 5.14 \\
\hline KQNKN & $87,576,960$ & 38.29 & 91.57 & 19.71 & $96,192,120$ & 25.90 & 74.41 & 8.99 \\
\hline KQNKQ & $87,576,960$ & 38.29 & 91.57 & 19.71 & $93,824,100$ & 29.08 & 78.82 & 11.74 \\
\hline KQNKR & $87,576,960$ & 38.29 & 91.57 & 19.71 & $98,951,760$ & 22.39 & 69.55 & 5.95 \\
\hline KQQKB & $41,944,320$ & 188.74 & 299.99 & 24.97 & $49,854,690$ & 142.93 & 236.52 & 5.14 \\
\hline KQQKN & $41,944,320$ & 188.74 & 299.99 & 24.97 & $48,096,060$ & 151.81 & 248.83 & 8.99 \\
\hline KQQKQ & $41,944,320$ & 188.74 & 299.99 & 24.97 & $46,912,050$ & 158.17 & 257.63 & 11.74 \\
\hline KQQKR & $41,944,320$ & 188.74 & 299.99 & 24.97 & $49,475,880$ & 144.79 & 239.10 & 5.95 \\
\hline KQRKB & $90,038,460$ & 34.51 & 86.33 & 16.44 & $99,709,380$ & 21.46 & 68.26 & 5.14 \\
\hline KQRKN & $90,038,460$ & 34.51 & 86.33 & 16.44 & $96,192,120$ & 25.90 & 74.41 & 8.99 \\
\hline KQRKQ & $90,038,460$ & 34.51 & 86.33 & 16.44 & $93,824,100$ & 29.08 & 78.82 & 11.74 \\
\hline KQRKR & $90,038,460$ & 34.51 & 86.33 & 16.44 & $98,951,760$ & 22.39 & 69.55 & 5.95 \\
\hline KRBKB & $95,673,600$ & 26.59 & 75.36 & 9.58 & $99,709,380$ & 21.46 & 68.26 & 5.14 \\
\hline KRBKN & $95,673,600$ & 26.59 & 75.36 & 9.58 & $96,192,120$ & 25.90 & 74.41 & 8.99 \\
\hline KRBKQ & $95,673,600$ & 26.59 & 75.36 & 9.58 & $93,824,100$ & 29.08 & 78.82 & 11.74 \\
\hline KRBKR & $95,673,600$ & 26.59 & 75.36 & 9.58 & $98,951,760$ & 22.39 & 69.55 & 5.95 \\
\hline KRNKB & $92,308,740$ & 31.20 & 81.75 & 13.57 & $99,709,380$ & 21.46 & 68.26 & 5.14 \\
\hline KRNKN & $92,308,740$ & 31.20 & 81.75 & 13.57 & $96,192,120$ & 25.90 & 74.41 & 8.99 \\
\hline KRNKQ & $92,308,740$ & 31.20 & 81.75 & 13.57 & $93,824,100$ & 29.08 & 78.82 & 11.74 \\
\hline KRNKR & $92,308,740$ & 31.20 & 81.75 & 13.57 & $98,951,760$ & 22.39 & 69.55 & 5.95 \\
\hline KRRKB & $46,658,340$ & 159.57 & 259.58 & 12.35 & $49,854,690$ & 142.93 & 236.52 & 5.14 \\
\hline KRRKN & $46,658,340$ & 159.57 & 259.58 & 12.35 & $48,096,060$ & 151.81 & 248.83 & 8.99 \\
\hline KRRKQ & $46,658,340$ & 159.57 & 259.58 & 12.35 & $46,912,050$ & 158.17 & 257.63 & 11.74 \\
\hline KRRKR & $46,658,340$ & 159.57 & 259.58 & 12.35 & $49,475,880$ & 144.79 & 239.10 & 5.95 \\
\hline Aggregate & $2,917,997,520$ & 66.02 & 129.98 & 14.97 & $3,109,418,880$ & 55.80 & 115.82 & 7.89 \\
\hline
\end{tabular}

Table 11: Comparison of index sizes for pawnless 3-2 endgames.

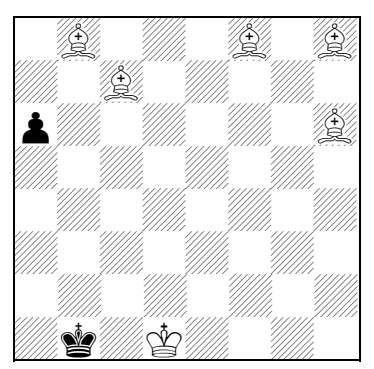

Figure 6: Troitzkiū (1905).

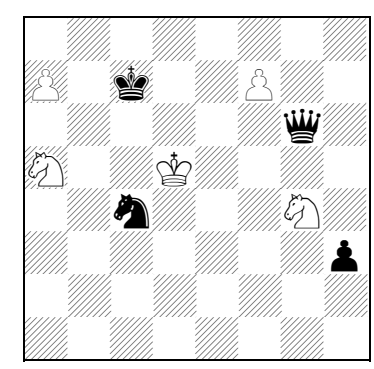

Figure 7: Troitzkiı̌ (1912).

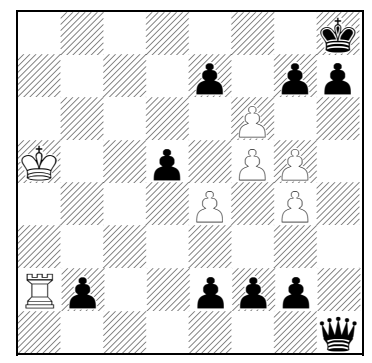

Figure 8: Bondar (1998). 
Beasley and Whitworth (1996), referring also to Savin and Plaksin (1987), cite the Troitzkii study of 1905, q.v. Figure 6, with 5 black-square Bishops as follows:

“1. Bce5 a5 2. Ba1 a4 3. Bbe5 Ka2 4. Kc2 a3 5. Kc3 K×a1 6. Kb3+ Kb1 7. Ba1 a2 8. Kc3 K×a1 Kc2\#.”

Elkies (2000) recalls the Troitzkiı̌ (1912) study, q.v. Figure 7, noting that Troitzkiǔ (1934) includes four pages of analysis proving the $4 \mathrm{~N}-w i n$ :

“1. a8N+ Kd7 2. f8N+ Kc8 3. N×g6 Ne3+ 4. N×e3 (not 4. Ke4 N×g4 5. Kf3 Ne3 6. Kg3 Nd5 =) h2 5. Nb6+ Kc7 6. Kc5 h1Q 7. Ned5+ Kd8 (7. ... Kb8 8. Nge7 Qg1+ 9. Kb5 Qf1+ 10. Nbc4 wins) 8. Nc6+ Ke8 9. Nce5 winning as Black is pushed slowly off the board, e.g. 9. ... Qc1+ 10. Kd6 Qa3+ 11. Kc6 Qc1+ (11. ... Qb3 12. Ngf4 Qc2+ 13. Kd6 Qd2 14. Ne6 Qb4+ 15. Nc5 Qa3 16. Nbd7 Qg3 17. Nc7+ Kd8 18. N5e6+ Kc8 19. Nd5 Qa3+ 20. Ndc5 wins ${ }^{10}$ ) 12. Nbc4 Kd8 13. Ngf4 Kc8 14. Ne6 Kb8 15. Kd7 wins ${ }^{11}$."

Bondar (1998) composed the study of Figure 8 featuring four losing black Queens:

1. f7 e1Q+ 2. Ka6 flQ+ 3. Ka7 g1Q+ 4. Ka8 Q×f5 5. g×f5 h5 6. g6 Q×g6 7. f8Q+ Kh7 8. f×g6+ Kh6 9. Qf4+ K×g6 10. Qf5+ Kh6 11. Ra6+ wins.

\begin{tabular}{|c|c|c|c|c|c|c|c|c|}
\hline & wtm & KT & SE & EH & btm & KT & SE & EH \\
\hline Endgame & \# Elements & $+\Delta \%$ & $+\Delta \%$ & $+\Delta \%$ & \# Elements & $+\Delta \%$ & $+\Delta \%$ & $+\Delta \%$ \\
\hline KBBKP & $148,223,520$ & 171.65 & 262.20 & 7.03 & $149,445,120$ & 169.43 & 259.24 & 6.15 \\
\hline KBNKP & $290,989,584$ & 38.37 & 84.50 & 9.03 & $298,890,240$ & 34.72 & 79.62 & 6.15 \\
\hline KBPKB & $289,027,680$ & 39.31 & 85.75 & 9.77 & $306,720,000$ & 31.28 & 75.04 & 3.44 \\
\hline KBPKN & $289,027,680$ & 39.31 & 85.75 & 9.77 & $295,914,240$ & 36.07 & 81.43 & 7.22 \\
\hline KBPKP & $227,896,016$ & 32.51 & 135.58 & 7.27 & $231,758,952$ & 30.30 & 131.65 & 5.48 \\
\hline KBPKQ & $289,027,680$ & 39.31 & 85.75 & 9.77 & $288,610,560$ & 39.51 & 86.02 & 9.93 \\
\hline KBPKR & $289,027,680$ & 39.31 & 85.75 & 9.77 & $304,369,920$ & 32.29 & 76.39 & 4.24 \\
\hline KNNKP & $137,991,648$ & 191.80 & 289.06 & 14.96 & $149,445,120$ & 169.43 & 259.24 & 6.15 \\
\hline KNPKB & $278,914,860$ & 44.36 & 92.49 & 13.75 & $306,720,000$ & 31.28 & 75.04 & 3.44 \\
\hline KNPKN & $278,914,860$ & 44.36 & 92.49 & 13.75 & $295,914,240$ & 36.07 & 81.43 & 7.22 \\
\hline KNPKP & $219,921,779$ & 37.32 & 144.12 & 11.16 & $231,758,952$ & 30.30 & 131.65 & 5.48 \\
\hline KNPKQ & $278,914,860$ & 44.36 & 92.49 & 13.75 & $288,610,560$ & 39.51 & 86.02 & 9.93 \\
\hline KNPKR & $278,914,860$ & 44.36 & 92.49 & 13.75 & $304,369,920$ & 32.29 & 76.39 & 4.24 \\
\hline KPPKB & $108,400,260$ & 178.59 & 395.27 & 15.16 & $120,132,000$ & 151.38 & 346.90 & 3.91 \\
\hline KPPKN & $108,400,260$ & 178.59 & 395.27 & 15.16 & $115,899,744$ & 160.56 & 363.22 & 7.71 \\
\hline KPPKP & $84,219,361$ & 168.93 & 537.47 & 11.27 & $89,391,280$ & 153.37 & 500.59 & 4.83 \\
\hline KPPKQ & $108,400,260$ & 178.59 & 395.27 & 15.16 & $113,036,880$ & 167.16 & 374.95 & 10.43 \\
\hline KPPKR & $108,400,260$ & 178.59 & 395.27 & 15.16 & $119,209,296$ & 153.33 & 350.36 & 4,72 \\
\hline KQBKP & $283,818,240$ & 41.87 & 89.16 & 11.79 & $298,890,240$ & 34.72 & 79.62 & 6.15 \\
\hline KQNKP & $273,904,512$ & 47.00 & 96.01 & 15.84 & $298,890,240$ & 34.72 & 79.62 & 6.15 \\
\hline KQPKB & $272,015,040$ & 48.03 & 97.37 & 16.64 & $306,720,000$ & 31.28 & 75.04 & 3.44 \\
\hline KQPKN & $272,015,040$ & 48.03 & 97.37 & 16.64 & $295,914,240$ & 36.07 & 81.43 & 7.22 \\
\hline KQPKP & $214,481,388$ & 40.80 & 150.31 & 13.98 & $231,758,952$ & 30.30 & 131.65 & 5.48 \\
\hline KQPKQ & $272,015,040$ & 48.03 & 97.37 & 16.64 & $288,610,560$ & 39.51 & 86.02 & 9.93 \\
\hline KQPKR & $272,015,040$ & 48.03 & 97.37 & 16.64 & $304,369,920$ & 32.29 & 76.39 & 4.24 \\
\hline KQQKP & $131,170,128$ & 206.97 & 309.29 & 20.94 & $149,445,120$ & 169.43 & 259.24 & 6.15 \\
\hline KQRKP & $281,568,240$ & 43.00 & 90.67 & 12.68 & $298,890,240$ & 34.72 & 79.62 & 6.15 \\
\hline KRBKP & $299,203,200$ & 34.58 & 79.43 & 6.04 & $298,890,240$ & 34.72 & 79.62 & 6.15 \\
\hline KRNKP & $288,692,928$ & 39.47 & 85.97 & 9.90 & $298,890,240$ & 34.72 & 79.62 & 6.15 \\
\hline KRPKB & $286,777,440$ & 40.41 & 87.21 & 10.64 & $306,720,000$ & 31.28 & 75.04 & 3.44 \\
\hline KRPKN & $286,777,440$ & 40.41 & 87.21 & 10.64 & $295,914,240$ & 36.07 & 81.43 & 7.22 \\
\hline KRPKP & $226,121,876$ & 33.55 & 137.43 & 8.11 & $231,758,952$ & 30.30 & 131.65 & 5.48 \\
\hline KRPKQ & $286,777,440$ & 40.41 & 87.21 & 10.64 & $288,610,560$ & 39.51 & 86.02 & 9.93 \\
\hline KRPKR & $286,777,440$ & 40.41 & 87.21 & 10.64 & $304,369,920$ & 32.29 & 76.39 & 4.24 \\
\hline KRRKP & $145,901,232$ & 175.98 & 267.97 & 8.73 & $149,445,120$ & 169.43 & 259.24 & 6.15 \\
\hline Aggregate & $8,194,644,772$ & 60.00 & 129.30 & 12.09 & $8,658,285,808$ & 51.43 & 117.02 & 6.09 \\
\hline
\end{tabular}

Table 12: Comparison of index sizes over 3-2 endgames with Pawns.

10 20. ... Qg3 21. Ne7+ Kb8 22. Ncd7+ Ka8 23. Nec5 Qf4 24. Kc7 Qb4 25. Nb6+ Q×b6+ 26. K×b6 Kb8 27. Na6+ Ka8 etc.

11 15. ... Q×c4 16. N×c4 Kb7 17. Nc5+Ka7 18. Kc7 Ka8 19. Ncb6+Ka7 20. Nc8+ Ka8 21. Ndb6\#. 


\begin{tabular}{|c|c|c|c|c|c|c|c|c|}
\hline & wtm & KT & SE & EH & btm & KT & SE & EH \\
\hline Endgame & \# Elements & $+\Delta \%$ & $+\Delta \%$ & $+\Delta \%$ & \# Elements & $+\Delta \%$ & $+\Delta \%$ & $+\Delta \%$ \\
\hline KBBBK & $15,010,230$ & 706.85 & 1017.72 & 16.41 & $17,472,840$ & 593.14 & 860.19 & 0.00 \\
\hline KBBNK & $44,983,618$ & 169.23 & 272.96 & 16.53 & $52,418,520$ & 131.05 & 220.06 & 0.00 \\
\hline KBBPK & $139,715,040$ & 188.20 & 284.26 & 13.54 & $153,741,960$ & 161.90 & 249.20 & 3.19 \\
\hline KBNNK & $43,406,294$ & 179.02 & 286.52 & 20.76 & $52,418,520$ & 131.05 & 220.06 & 0.00 \\
\hline KBNPK & $274,352,939$ & 46.76 & 95.69 & 15.65 & $307,483,920$ & 30.95 & 74.60 & 3.19 \\
\hline KBPPK & $106,602,156$ & 183.29 & 403.62 & 17.10 & $114,742,320$ & 163.19 & 367.89 & 8.79 \\
\hline KNNNK & $13,486,227$ & 798.03 & 1144.03 & 29.56 & $17,472,840$ & 593.14 & 860.19 & 0.00 \\
\hline KNNPK & $130,135,501$ & 209.41 & 312.55 & 21.90 & $153,741,960$ & 161.90 & 249.20 & 3.19 \\
\hline KNPPK & $102,898,651$ & 193.48 & 421.75 & 21.31 & $114,742,320$ & 163.19 & 367.89 & 8.79 \\
\hline KPPPK & $26,061,704$ & 769.06 & 1960.00 & 20.36 & $28,388,716$ & 697.83 & 1791.14 & 10.49 \\
\hline KQBBK & $43,879,679$ & 176.01 & 282.35 & 19.46 & $52,418,520$ & 131.05 & 220.06 & 0.00 \\
\hline KQBNK & $86,166,717$ & 40.55 & 94.71 & 21.67 & $104,837,040$ & 15.52 & 60.03 & 0.00 \\
\hline KQBPK & $267,576,632$ & 50.48 & 100.64 & 18.57 & $307,483,920$ & 30.95 & 74.60 & 3.19 \\
\hline KQNNK & $40,873,646$ & 196.30 & 310.47 & 28.25 & $52,418,520$ & 131.05 & 220.06 & 0.00 \\
\hline KQNPK & $258,294,639$ & 55.89 & 107.85 & 22.84 & $307,483,920$ & 30.95 & 74.60 & 3.19 \\
\hline KQPPK & $100,347,220$ & 200.94 & 435.01 & 24.40 & $114,742,320$ & 163.19 & 367.89 & 8.79 \\
\hline KQQBK & $41,270,973$ & 193.45 & 306.51 & 27.01 & $52,418,520$ & 131.05 & 220.06 & 0.00 \\
\hline KQQNK & $39,840,787$ & 203.99 & 321.11 & 31.57 & $52,418,520$ & 131.05 & 220.06 & 0.00 \\
\hline KQQPK & $123,688,859$ & 225.54 & 334.05 & 28.26 & $153,741,960$ & 161.90 & 249.20 & 3.19 \\
\hline KQQQK & $12,479,974$ & 870.44 & 1244.33 & 40.01 & $17,472,840$ & 593.14 & 860.19 & 0.00 \\
\hline KQQRK & $40,916,820$ & 195.99 & 310.03 & 28.11 & $52,418,520$ & 131.05 & 220.06 & 0.00 \\
\hline KQRBK & $88,557,959$ & 36.76 & 89.45 & 18.38 & $104,837,040$ & 15.52 & 60.03 & 0.00 \\
\hline KQRNK & $85,470,603$ & 41.70 & 96.29 & 22.66 & $104,837,040$ & 15.52 & 60.03 & 0.00 \\
\hline KQRPK & $265,421,907$ & 51.70 & 102.27 & 19.54 & $307,483,920$ & 30.95 & 74.60 & 3.19 \\
\hline KQRRK & $43,157,690$ & 180.62 & 288.74 & 21.46 & $52,418,520$ & 131.05 & 220.06 & 0.00 \\
\hline KRBBK & $46,242,089$ & 161.91 & 262.81 & 13.36 & $52,418,520$ & 131.05 & 220.06 & 0.00 \\
\hline KRBNK & $90,787,358$ & 33.40 & 84.80 & 15.48 & $104,837,040$ & 15.52 & 60.03 & 0.00 \\
\hline KRBPK & $281,991,360$ & 42.79 & 90.39 & 12.51 & $307,483,920$ & 30.95 & 74.60 & 3.19 \\
\hline KRNNK & $43,056,198$ & 181.28 & 289.66 & 21.74 & $52,418,520$ & 131.05 & 220.06 & 0.00 \\
\hline KRNPK & $272,153,675$ & 47.95 & 97.27 & 16.58 & $307,483,920$ & 30.95 & 74.60 & 3.19 \\
\hline KRPPK & $105,758,666$ & 185.55 & 407.64 & 18.03 & $114,742,320$ & 163.19 & 367.89 & 8.79 \\
\hline KRRBK & $45,873,720$ & 164.01 & 265.73 & 14.27 & $52,418,520$ & 131.05 & 220.06 & 0.00 \\
\hline KRRNK & $44,265,261$ & 173.60 & 279.02 & 18.42 & $52,418,520$ & 131.05 & 220.06 & 0.00 \\
\hline KRRPK & $137,491,197$ & 192.86 & 290.48 & 15.38 & $153,741,960$ & 161.90 & 249.20 & 3.19 \\
\hline KRRRK & $14,644,690$ & 726.99 & 1045.62 & 19.31 & $17,472,840$ & 593.14 & 860.19 & 0.00 \\
\hline Aggregate & $3,516,860,679$ & 124.15 & 224.39 & 19.06 & $4,065,491,116$ & 93.91 & 180.62 & 2.99 \\
\hline
\end{tabular}

Table 13: Comparison of index ranges over 4-1 endgames.

\begin{tabular}{|c|c|c|c|c|c|c|c|c|c|}
\hline \multirow[b]{3}{*}{ Endgame } & \multicolumn{4}{|c|}{ Broken Positions } & \multirow[b]{3}{*}{ Endgame } & \multicolumn{4}{|c|}{ Broken Positions } \\
\hline & \multicolumn{2}{|l|}{ wtm } & \multicolumn{2}{|l|}{ btm } & & \multicolumn{2}{|l|}{ wtm } & \multicolumn{2}{|l|}{ btm } \\
\hline & \# & $\%$ & \# & $\%$ & & \# & $\%$ & \# & $\%$ \\
\hline KBBBK & $3,795,425$ & 25.29 & 0 & 0.00 & KBNKN & $9,252,139$ & 9.94 & 0 & 0.00 \\
\hline KBBK & 139,093 & 17.61 & 0 & 0.00 & KBNKP & $44,907,128$ & 15.43 & 0 & 0.00 \\
\hline KBBKB & $8,055,627$ & 17.00 & $4,272,301$ & 8.57 & KBNKQ & $9,252,139$ & 9.94 & $24,074,338$ & 25.66 \\
\hline KBBKN & $8,055,627$ & 17.00 & 0 & 0.00 & KBNKR & $9,252,139$ & 9.94 & $15,529,736$ & 15.69 \\
\hline KBBKP & $32,609,914$ & 22.00 & 0 & 0.00 & KBNNK & $4,915,218$ & 11.32 & 0 & 0.00 \\
\hline KBBKQ & $8,055,627$ & 17.00 & $12,037,169$ & 25.66 & KBNPK & $35,301,529$ & 12.87 & 0 & 0.00 \\
\hline KBBKR & $8,055,627$ & 17.00 & $7,764,868$ & 15.69 & KBPK & 500,513 & 10.39 & 0 & 0.00 \\
\hline KBBNK & $8,769,335$ & 19.49 & 0 & 0.00 & KBPKB & $29,140,721$ & 10.08 & $39,073,198$ & 12.74 \\
\hline KBBPK & $27,592,969$ & 19.75 & 0 & 0.00 & KBPKN & $29,140,721$ & 10.08 & $13,658,280$ & 4.62 \\
\hline KBK & 2,507 & 9.20 & 0 & 0.00 & КВРКР & $32,514,553$ & 14.27 & $7,406,518$ & 3.20 \\
\hline KВКB & 147,587 & 8.88 & 147,587 & 8.88 & KBPKQ & $29,140,721$ & 10.08 & $83,399,904$ & 28.90 \\
\hline KBKN & 147,587 & 8.88 & 0 & 0.00 & KBPKR & $29,140,721$ & 10.08 & $59,322,146$ & 19.49 \\
\hline KBKP & 666,320 & 13.03 & 0 & 0.00 & KBPPK & $12,305,285$ & 11.54 & 0 & 0.00 \\
\hline KBNK & 158,939 & 10.25 & 0 & 0.00 & KK & 0 & 0.00 & 0 & 0.00 \\
\hline KBNKB & $9,252,139$ & 9.94 & $8,544,602$ & 8.57 & KNK & 0 & 0.00 & 0 & 0.00 \\
\hline
\end{tabular}

Table 14a: Numbers and Percentages of Broken Positions in Nalimov's EGTs. 


\begin{tabular}{|c|c|c|c|c|c|c|c|c|c|}
\hline \multirow[b]{3}{*}{ Endgame } & \multicolumn{4}{|c|}{ Broken Positions } & & \multicolumn{4}{|c|}{ Broken Positions } \\
\hline & \multicolumn{2}{|l|}{ wtm } & \multicolumn{2}{|l|}{ btm } & \multirow[b]{2}{*}{ Endgame } & \multicolumn{2}{|l|}{ wtm } & \multicolumn{2}{|l|}{ btm } \\
\hline & \# & $\%$ & \# & $\%$ & & \# & $\%$ & \# & $\%$ \\
\hline KNKN & 0 & 0.00 & 0 & 0.00 & KQQKB & $19,489,387$ & 46.46 & $4,272,301$ & 8.57 \\
\hline KNKP & 227,638 & 4.62 & 0 & 0.00 & KQQKN & $19,489,387$ & 46.46 & 0 & 0.00 \\
\hline KNNK & 0 & 0.00 & 0 & 0.00 & KQQKP & $64,878,086$ & 49.46 & 0 & 0.00 \\
\hline KNNKB & 0 & 0.00 & 616,152 & 1.24 & KQQKQ & $19,489,387$ & 46.46 & $12,037,169$ & 25.66 \\
\hline KNNKN & 0 & 0.00 & 0 & 0.00 & KQQKR & $19,489,387$ & 46.46 & $7,764,868$ & 15.69 \\
\hline KNNKP & $8,479,456$ & 6.14 & 0 & 0.00 & KQQNK & $19,083,485$ & 47.90 & 0 & 0.00 \\
\hline KNNKQ & 0 & 0.00 & $12,037,169$ & 25.66 & KQQPK & $59,373,739$ & 48.00 & 0 & 0.00 \\
\hline KNNKR & 0 & 0.00 & $7,764,868$ & 15.69 & KQQQK & $7,854,527$ & 62.94 & 0 & 0.00 \\
\hline KNNNK & 0 & 0.00 & 0 & 0.00 & KQQRK & $23,835,461$ & 58.25 & 0 & 0.00 \\
\hline KNNPK & $4,136,099$ & 3.18 & 0 & 0.00 & KQRBK & $41,394,865$ & 46.74 & 0 & 0.00 \\
\hline KNPK & 73,856 & 1.59 & 0 & 0.00 & KQRK & 616,152 & 41.07 & 0 & 0.00 \\
\hline KNPKB & $4,431,360$ & 1.59 & $39,073,198$ & 12.74 & KQRKB & $35,638,322$ & 39.58 & $8,544,602$ & 8.57 \\
\hline KNPKN & $4,431,360$ & 1.59 & $13,658,280$ & 4.62 & KQRKN & $35,638,322$ & 39.58 & 0 & 0.00 \\
\hline KNPKP & $13,811,226$ & 6.28 & $7,406,518$ & 3.20 & KQRKP & $121,235,002$ & 43.06 & 0 & 0.00 \\
\hline KNPKQ & $4,431,360$ & 1.59 & $83,399,904$ & 28.90 & KQRKQ & $35,638,322$ & 39.58 & $24,074,338$ & 25.66 \\
\hline KNPKR & $4,431,360$ & 1.59 & $59,322,146$ & 19.49 & KQRKR & $35,638,322$ & 39.58 & $15,529,736$ & 15.69 \\
\hline KNPPK & $3,270,048$ & 3.18 & 0 & 0.00 & KQRNK & $35,307,376$ & 41.31 & 0 & 0.00 \\
\hline KPK & 0 & 0.00 & 0 & 0.00 & KQRPK & $109,627,138$ & 41.30 & 0 & 0.00 \\
\hline KPKP & 123,555 & 3.20 & 123,555 & 3.20 & KQRRK & $22,457,809$ & 52.04 & 0 & 0.00 \\
\hline KPPK & 0 & 0.00 & 0 & 0.00 & KRBBK & $14,750,918$ & 31.90 & 0 & 0.00 \\
\hline KPРКB & 0 & 0.00 & $20,104,876$ & 16.74 & KRBK & 396,136 & 24.84 & 0 & 0.00 \\
\hline KPPKN & 0 & 0.00 & $10,532,252$ & 9.09 & KRBKB & $22,924,278$ & 23.96 & $8,544,602$ & 8.57 \\
\hline KPPKP & $2,854,365$ & 3.39 & $5,664,886$ & 6.34 & KRBKN & $22,924,278$ & 23.96 & 0 & 0.00 \\
\hline KPPKQ & 0 & 0.00 & $36,200,376$ & 32.03 & KRBKP & $85,322,108$ & 28.52 & 0 & 0.00 \\
\hline KPPKR & 0 & 0.00 & $27,657,596$ & 23.20 & KRBKQ & $22,924,278$ & 23.96 & $24,074,338$ & 25.66 \\
\hline KPPPK & 0 & 0.00 & 0 & 0.00 & KRBKR & $22,924,278$ & 23.96 & $15,529,736$ & 15.69 \\
\hline KQBBK & $18,081,566$ & 41.21 & 0 & 0.00 & KRBNK & $23,847,355$ & 26.27 & 0 & 0.00 \\
\hline KQBK & 526,735 & 34.83 & 0 & 0.00 & KRBPK & $74,211,659$ & 26.32 & 0 & 0.00 \\
\hline KQBKB & $30,490,930$ & 33.60 & $8,544,602$ & 8.57 & KRK & 4,630 & 17.13 & 0 & 0.00 \\
\hline KQBKN & $30,490,930$ & 33.60 & 0 & 0.00 & KRKB & 270,560 & 16.41 & 147,587 & 8.88 \\
\hline KQBKP & $106,356,738$ & 37.47 & 0 & 0.00 & KRKN & 270,560 & 16.41 & 0 & 0.00 \\
\hline KQBKQ & $30,490,930$ & 33.60 & $24,074,338$ & 25.66 & KRKP & $1,022,716$ & 20.16 & 0 & 0.00 \\
\hline KQBKR & $30,490,930$ & 33.60 & $15,529,736$ & 15.69 & KRKR & 270,560 & 16.41 & 270,560 & 16.41 \\
\hline KQBNK & $30,583,209$ & 35.49 & 0 & 0.00 & KRNK & 271,935 & 17.68 & 0 & 0.00 \\
\hline KQBPK & $95,439,748$ & 35.67 & 0 & 0.00 & KRNKB & $15,669,550$ & 16.98 & $8,544,602$ & 8.57 \\
\hline KQK & 7,137 & 27.85 & 0 & 0.00 & KRNKN & $15,669,550$ & 16.98 & 0 & 0.00 \\
\hline KQKB & 418,147 & 26.74 & 147,587 & 8.88 & KRNKP & $63,487,156$ & 21.99 & 0 & 0.00 \\
\hline KQKN & 418,147 & 26.74 & 0 & 0.00 & KRNKQ & $15,669,550$ & 16.98 & $24,074,338$ & 25.66 \\
\hline KQKP & $1,439,112$ & 29.92 & 0 & 0.00 & KRNKR & $15,669,550$ & 16.98 & $15,529,736$ & 15.69 \\
\hline KQKQ & 418,147 & 26.74 & 418,147 & 26.74 & KRNNK & $7,861,335$ & 18.26 & 0 & 0.00 \\
\hline KQKR & 418,147 & 26.74 & 270,560 & 16.41 & KRNPK & $53,055,381$ & 19.49 & 0 & 0.00 \\
\hline KQNK & 404,593 & 27.72 & 0 & 0.00 & KRPK & 840,944 & 17.59 & 0 & 0.00 \\
\hline KQNKB & $23,344,829$ & 26.66 & $8,544,602$ & 8.57 & KRPKB & $48,472,746$ & 16.90 & $39,073,198$ & 12.74 \\
\hline KQNKN & $23,344,829$ & 26.66 & 0 & 0.00 & KRPKN & $48,472,746$ & 16.90 & $13,658,280$ & 4.62 \\
\hline KQNKP & $84,872,244$ & 30.99 & 0 & 0.00 & KRPKP & $47,046,257$ & 20.81 & $7,406,518$ & 3.20 \\
\hline KQNKQ & $23,344,829$ & 26.66 & $24,074,338$ & 25.66 & KRPKQ & $48,472,746$ & 16.90 & $83,399,904$ & 28.90 \\
\hline KQNKR & $23,344,829$ & 26.66 & $15,529,736$ & 15.69 & KRPKR & $48,472,746$ & 16.90 & $59,322,146$ & 19.49 \\
\hline KQNNK & $11,305,947$ & 27.66 & 0 & 0.00 & KRPPK & $19,194,662$ & 18.15 & 0 & 0.00 \\
\hline KQNPK & $74,628,435$ & 28.89 & 0 & 0.00 & KRRBK & $17,408,683$ & 37.95 & 0 & 0.00 \\
\hline KQPK & $1,259,793$ & 27.79 & 0 & 0.00 & KRRK & 245,132 & 31.54 & 0 & 0.00 \\
\hline KQPKB & $72,713,627$ & 26.73 & $39,073,198$ & 12.74 & KRRKB & $14,121,920$ & 30.27 & $4,272,301$ & 8.57 \\
\hline KQPKN & $72,713,627$ & 26.73 & $13,658,280$ & 4.62 & KRRKN & $14,121,920$ & 30.27 & 0 & 0.00 \\
\hline KQPKP & $64,376,740$ & 30.02 & $7,406,518$ & 3.20 & KRRKP & $50,151,272$ & 34.37 & 0 & 0.00 \\
\hline KQPKQ & $72,713,627$ & 26.73 & $83,399,904$ & 28.90 & KRRKQ & $14,121,920$ & 30.27 & $12,037,169$ & 25.66 \\
\hline KQPKR & $72,713,627$ & 26.73 & $59,322,146$ & 19.49 & KRRKR & $14,121,920$ & 30.27 & $7,764,868$ & 15.69 \\
\hline KQPPK & $27,886,605$ & 27.79 & 0 & 0.00 & KRRNK & $14,334,054$ & 32.38 & 0 & 0.00 \\
\hline KQQBK & $22,021,058$ & 53.36 & 0 & 0.00 & KRRPK & $44,331,316$ & 32.24 & 0 & 0.00 \\
\hline KQQK & 336,585 & 48.17 & 0 & 0.00 & KRRRK & $6,387,602$ & 43.62 & 0 & 0.00 \\
\hline
\end{tabular}

Table 14b: Numbers and Percentages of Broken Positions in Nalimov's EGTs. 